OPEN ACCESS

Edited by:

Dorota Skowronska-Krawczyk,

UC Irvine Health System,

United States

Reviewed by:

Giulia Bertolin,

UMR6290 Institut de Genetique et

Developpement de Rennes (IGDR),

France

Wei Min,

Columbia University, United States Ammasi Periasamy,

University of Virginia, United States

${ }^{*}$ Correspondence:

Lingyan Shi

Lingyanshi@ucsd.edu

Specialty section:

This article was submitted to

Aging, Metabolism and Redox Biology, a section of the journal

Frontiers in Aging

Received: 22 November 2021 Accepted: 29 December 2021

Published: 03 February 2022

Citation:

Li Y, Bagheri $P$, Chang $P$, Zeng $A$, Hao J, Fung A, Wu JY and Shi L (2022)

Direct Imaging of Lipid Metabolic Changes in Drosophila Ovary During

Aging Using DO-SRS Microscopy.

Front. Aging 2:819903.

doi: 10.3389/fragi.2021.819903

\section{Direct Imaging of Lipid Metabolic Changes in Drosophila Ovary During Aging Using DO-SRS Microscopy}

Yajuan $\mathrm{Li}^{1}$, Pegah Bagheri ${ }^{1}$, Phyllis Chang ${ }^{1}$, Audrey Zeng ${ }^{1}$, Jie Hao ${ }^{1}$, Anthony Fung ${ }^{1}$, Jane $Y . W u^{2}$ and Lingyan Shi ${ }^{1 *}$

${ }^{1}$ The Department of Bioengineering, University of California San Diego, La Jolla, CA, United States, ${ }^{2}$ Department of Neurology, Northwestern University, Chicago, IL, United States

Emerging studies have shown that lipids and proteins play versatile roles in various aspects of aging. High-resolution in situ optical imaging provides a powerful approach to study the metabolic dynamics of lipids and proteins during aging. Here, we integrated $\mathrm{D}_{2} \mathrm{O}$ probing and stimulated Raman scattering (DO-SRS) microscopy to directly visualize metabolic changes in aging Drosophila ovary. The subcellular spatial distribution of de novo protein synthesis and lipogenesis in ovary was quantitatively imaged and examined. Our Raman spectra showed that early stages follicles were protein-enriched whereas mature eggs were lipid-enriched. DO-SRS imaging showed a higher protein synthesis in the earlier developing stages and an increased lipid turned over at the late stage. Aged (35 days) flies exhibited a dramatic decrease in metabolic turnover activities of both proteins and lipids, particularly, in the germ stem cell niche of germarium. We found an accumulation of unsaturated lipids in the nurse cells and oocytes in old flies, suggesting that unsaturated lipids may play an important role in the processes of oocyte maturation. We further detected changes in mitochondrial morphology and accumulation of Cytochrome c during aging. To our knowledge, this is the first study that directly visualizes spatiotemporal changes in lipid and protein metabolism in Drosophila ovary during development and aging processes. Our study not only demonstrates the application of a new imaging platform in visualizing metabolic dynamics of lipids and proteins in situ but also unravels how the metabolic activity and lipid distribution change in Drosophila ovary during aging.

Keywords: stimulated Raman scattering, DO-SRS, lipid metabolism, aging, ovary, Drosophila, heavy water, metabolic dynamics

\section{INTRODUCTION}

Accumulating evidence indicates that the quantitative and qualitative changes in stem cells with time contribute to aging and age-related diseases (Katajisto et al., 2015; Hinnant et al., 2020; Na and Kim, 2020). Genetic and epigenetic pathways involved in stem cell maintenance, division, and differentiation have been identified to be evolutionarily conserved, including the hedgehog, wingless, JAK/STAT, insulin, and TGF- $\beta$ (Hsu et al., 2008; Kosan and Godmann, 2016; Jeong et al., 2019). Drosophila, especially its ovary, provides a sophisticated model system to study stem cell aging (Knoblich, 2008; Katajisto et al., 2015; Hinnant et al., 2020; Tiwari and Mandal, 2021). There are two types of stem cells inside Drosophila ovary: the germ-line stem cells that generate oocytes and their supporting nurse cells, and the somatic stem cells that give rise to the 
surrounding follicular epithelium (Knoblich, 2008; Garcez et al., 2020; Hinnant et al., 2020; Doherty et al., 2021; Tiwari and Mandal, 2021). Similar to mammals, ovarian aging in Drosophila results in the decline of reproductive function that is characterized by reduced quality and quantity of eggs (Moghadam et al., 2021).

Among different mechanisms of ovarian aging, metabolic changes have attracted much attention since metabolism of ovary impacts the quality of oocyte and the development of embryo. Dysregulation of protein homeostasis during aging has been well understood as a causal factor of low-quality germ cells (Duncan and Gerton, 2018). For example, the oocytes generated from elder individuals have shown increased fibrillarin expression in humans (Yang et al., 2019; Wang and $\mathrm{Na}$, 2021). Association of lipid metabolism in ovary development and aging has also been increasingly recognized. However, changes in metabolic activity and specific chemical molecule that influence the function of ovary during aging have not been clearly deciphered yet. Understanding this dynamics of metabolism during aging is important and will provide insights into molecular mechanisms underlying premature ovarian failure and infertility diseases (Zhang et al., 2019a; Baddela et al., 2020).

Common analytical and imaging techniques have limitations. For example, gas chromatography (GC) needs long-time sample preparation, mass spectrometry (MS)-based techniques or matrix-assisted laser desorption/ionization (MALDI)-MS imaging are destructive to live tissues, nuclear magnetic resonance (NMR) spectroscopy has relatively low spatial resolution, and fluorescence microscopy requires bulky fluorescent dyes that may disturb the activities of native molecules.

As a nondestructive technique, Raman spectroscopy has been widely used since the past decades, which is based on the inelastic scattering of light by vibrating molecules (Raman scattering). Different chemical bonds vibrate at different frequencies, giving distinct fingerprints of molecules in the Raman spectrum. Thus, each peak in a Raman spectrum corresponds to certain chemical bonds' vibrational modes. Furthermore, the intensity of Raman scattering signal has a linear relationship to the concentration of a molecule's chemical bonds, which allows for quantitative imaging. One drawback of spontaneous Raman is its weak signal intensity that greatly limits imaging speed for visualizing metabolic dynamics in living organisms. Stimulated Raman scattering (SRS) and heavy water $\left(\mathrm{D}_{2} \mathrm{O}\right)$ probed-SRS (DO-SRS) microscopy have emerged as new imaging techniques in the past decade with much faster imaging speed ( 1,000 times faster than spontaneous Raman scattering). SRS uses two laser sources to coherently excite the vibration of molecules. When the energy difference between these two laser beams matches the vibrational frequency of a molecule of interest in the tissues, the transition rate can be dramatically enhanced up to $10^{8}$-fold. With this level of sensitivity, either of these two beams can be used as the source for video rate imaging. SRS imaging is advantageous in its multiplex imaging capability, high subcellular resolution and chemical specificity, and noninvasiveness (Ghita et al., 2012; Kong et al., 2013; Ember et al., 2017). Heavy water
(D2O) has been applied as a Raman probe to identify and sort metabolic activities of microbial cells by tracking the incorporation of $\mathrm{D}_{2} \mathrm{O}$-derived deuterium labeled macromolecules into bacteria (Berry et al., 2015). We recently established a new imaging platform that combined $\mathrm{D}_{2} \mathrm{O}$ probing with SRS microscopy for in situ visualization of metabolic dynamics at subcellular scale in small animals (Shi et al., 2018; Bagheri et al., 2021; Li et al., 2021). As an isotopologue of water, $\mathrm{D}_{2} \mathrm{O}$ can diffuse freely into living cells and tissues, where the deuterium (D) from $\mathrm{D}_{2} \mathrm{O}$ will be incorporated with carbon (C) atoms to form $\mathrm{C}-\mathrm{D}$ bonds in newly synthesized biomolecules such as lipids and protein through metabolism. The C-D bonds produce distinct peaks in the "cell-silent" region of Raman spectra (wavelength $1,800-2,800 \mathrm{~cm}^{-1}$ ), and by investigating the C-D vibrational spectra, we identified C-D bondcontaining molecules. Furthermore, applying DO-SRS microscopy imaging we directly visualized the metabolic dynamics of proteins, lipids, and DNA in living cells and animals including C. elegans, zebrafish, Drosophila, and mouse. In this study, we first integrated $\mathrm{D}_{2} \mathrm{O}$ probing with Raman spectroscopy to identify C-D spectra of lipid and protein in aging Drosophila ovary, and then applied DO-SRS microscopy to image and track metabolic dynamics of Drosophila ovarian follicles in situ during development. We quantitatively monitored changes in lipid and protein biosyntheses. Moreover, by comparing the ratiometric images of different lipid subtypes in young and aged flies, we demonstrated the lipid profile changes in ovary during the aging process.

\section{RESULTS}

\section{Label-free Raman Imaging of Drosophila Ovariole Development}

The Drosophila ovary consists of two lobes that are connected by a common oviduct. Each lobe is composed of approximately 14-16 ovarioles where the ovariole harbors an anterior localized germarium, following older follicles. Within the germarium, germline stem cells (GSCs) are surrounded by the somatic cells. One GSC generates two daughter cells, a GSC and cystoblast, through unsymmetric mitosis. Each cystoblast divides to form nurse cells (nc) and an oocyte (oo). Follicle stem cells (FSC) divide and differentiate to different kinds of specialized follicle cells (fc) that support germ cells. The mature oocyte is localized at the posterior end of each ovariole (Figure 1A), and Drosophila oogenesis is fueled by the activity of germline stem cells (Hinnant et al., 2020).

We measured the Raman spectra from fixed ovarioles of 5day-old females at 6 different stages: germarium, the developing follicle stage 1 , stage 3 , stage 5 , stage 8 , and the mature oocyte at stage 14 (Figure 1A) to determine biomolecular changes in distribution and quantity during development.

To have a more comprehensive picture Raman spectra were measured in the fingerprint region $\left(400-1800 \mathrm{~cm}^{-1}\right)$ and the $\mathrm{CH}$ stretching region $\left(2,800-3,050 \mathrm{~cm}^{-1}\right)$, respectively (Figures 1B,C). Assignment of prominent peaks is summarized in 

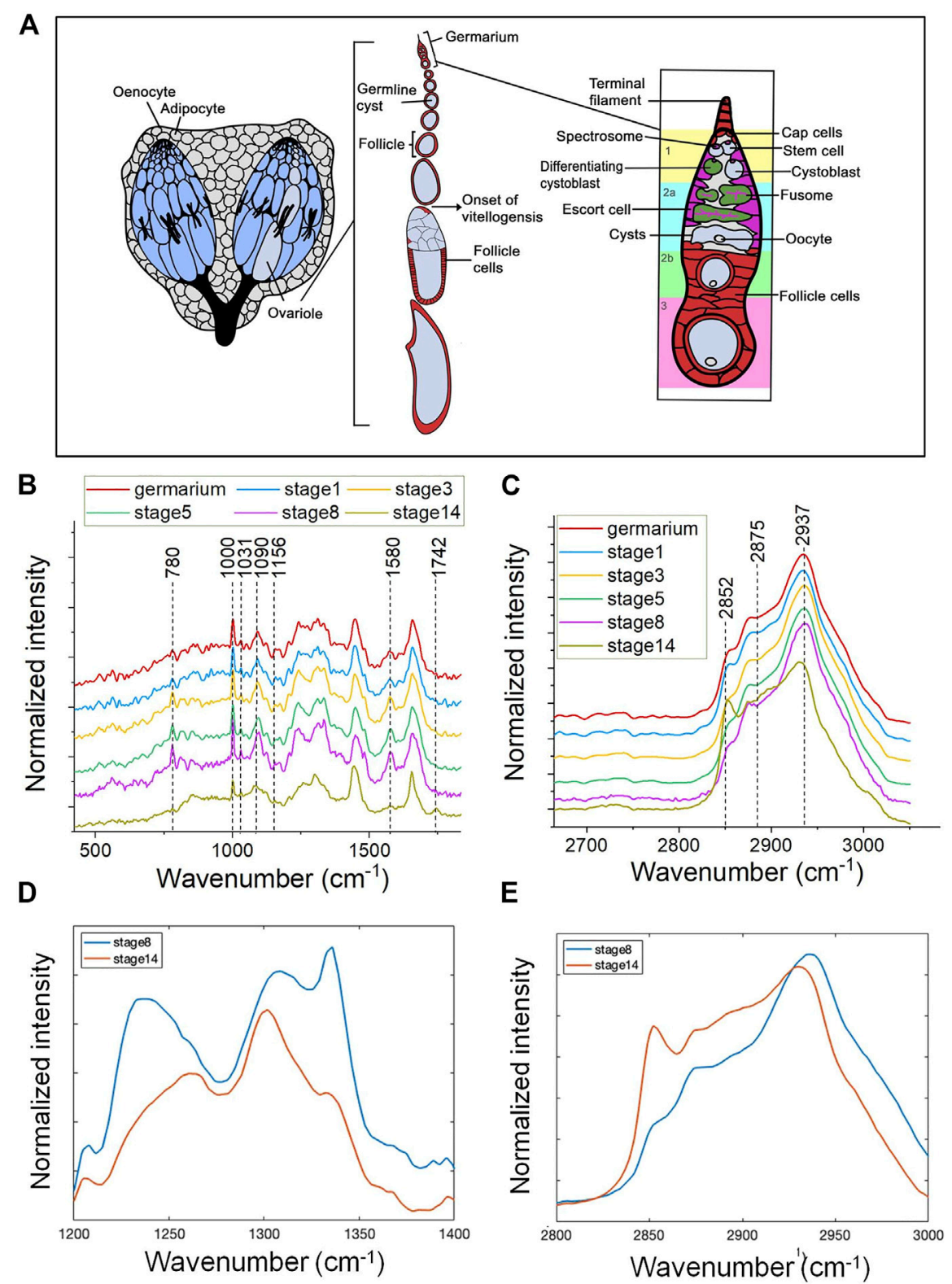

E

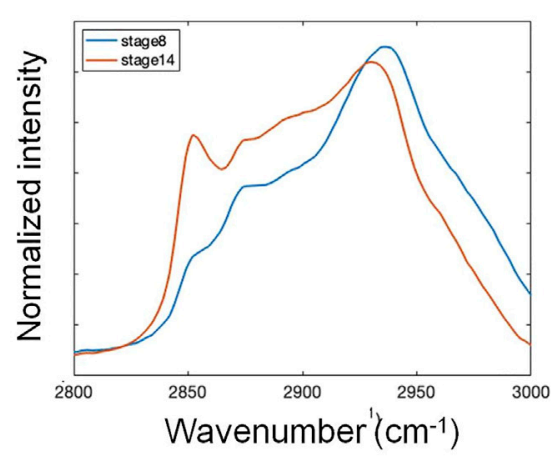

FIGURE 1 | Spontaneous Raman spectra of Drosophila ovaries revealing molecular changes during oogensis. (A) A diagrammatic illustration of the structure of adult ovary. The Drosophila ovary consists of two lobes that are connected by a common oviduct. Each lobe is composited of approximately 14-16 ovarioles. Each ovariole harbors an anterior localized germarium and following older follicles that develop through 14 distinct stages. Within the germarium, germline stem cells (GSCs) are surrounded by cap cells and escort cells, two major cellular components of the somatic niche. One GSC generates two daughter cells through unsymmetric mitosis, one is GSC and the other one is cystoblast. Each cystoblast divides four additional times to form 16-cell germline cysts consisted of nurse cells (nc) and an oocyte (Oo). Follicle stem cells (FSC) divide to form prefollicle cells, which surround the 16-cell germline cyst, and isolate them from the germarium. Prefollicle cells give rise to different kinds of specialized follicle cells (fc) that localized in an epithelial monolayer surrounding each cyst. The mature oocyte is localized at the posterior end of each ovariole. The fingerprint region (B) and $\mathrm{CH}$ stretching region (C) of mean Raman spectra $(n=10)$ of follicles at different developmental stages in 5-day female flies. (B) Compared with the mature oocyte, germarium and the developing follicles show a relatively high intensity of Raman peaks at $780 \mathrm{~cm}^{-1}, 1,000 \mathrm{~cm}^{-1}$, and $1,580 \mathrm{~cm}^{-1}$ and these peaks show a gradually higher intensity alongside the follicle maturation. There is a shape remodeling of amide III in the last stage of oogenesis (stage 14), which is different from the early stages. (C) A dramatically high intensity at $2,852 \mathrm{~cm}^{-1}$ is shown in stage 14 oocytes and the peak position of stage 14 oocytes at $2,937 \mathrm{~cm}^{-1}$ is relatively left-shifted. (D) The enlarged amide III region and (E) CH stretching region comparing the Raman spectral shape from stage 8 (blue) and stage 14 (red) follicle. Early developing follicles (stage 8) showed more protein enriched, and mature eggs (stage 14) showed more likely lipid dominated.

Table 1. In particular, we observed prominent changes at peaks $780 \mathrm{~cm}^{-1}, 1,000 \mathrm{~cm}^{-1}$, and $1,580 \mathrm{~cm}^{-1}$, which correspond to the vibrational modes of $\mathrm{C}-\mathrm{O}$ backbone in nucleic acids, the ring breathing mode of phenylalanine (Puppels et al., 1990), and Cytochrome c (Draga et al., 2010; Kumamoto et al., 2018; Hniopek et al., 2021), respectively. 
TABLE 1 | The chemical bond assignment of Raman peaks of Drosophila ovary.

\begin{tabular}{|c|c|}
\hline & - \\
\hline $716-720 \mathrm{~cm}-1$ & Phosphatidylcholine \\
\hline $753 \mathrm{~cm}-1$ & Tryptophan \\
\hline $780-784 \mathrm{~cm}-1$ & DNA \\
\hline $818 \mathrm{~cm}-1$ & RNA/DNA backbone \\
\hline $850-856 \mathrm{~cm}-1$ & Glycogen or tyrosine \\
\hline $1,000 \mathrm{~cm}-1$ & Phenylalanine \\
\hline $1,031 \mathrm{~cm}-1$ & $\mathrm{C}-\mathrm{H}$ in plane bending of Phenylalanine \\
\hline $1,087-1,090 \mathrm{~cm}-1$ & DNA backbone \\
\hline $1,125 \mathrm{~cm}-1$ & $\mathrm{C}-\mathrm{N}$ or $\mathrm{C}-\mathrm{O}$ carbohydrate \\
\hline $1,152-1,160$ and $1,520 \mathrm{~cm}-1$ & Carotenoid \\
\hline $1,200-1,300 \mathrm{~cm}-1$ & Amide III: C-N stretching and $\mathrm{N}-\mathrm{H}$ bending \\
\hline $1,260 \mathrm{~cm}-1$ in Amide III & $\beta$-sheets and random coils \\
\hline 1,300 in Amide III & A-helices \\
\hline $1,338 \mathrm{~cm}-1$ & Tryptophan \\
\hline $1,402 \mathrm{~cm}-1(1,410 \mathrm{~cm}-1)$ & COO-symmetric stretch of aspartic and glutamic acid residues, indicates that most acid side chains are deprotonated \\
\hline $1,430 \mathrm{~cm}-1$ & $\mathrm{CH} 2$ scissoring \\
\hline $1,443 \mathrm{~cm}-1$ & $\mathrm{CH} 2, \mathrm{CH} 3$ deformation of lipids and triglycerides \\
\hline $1,453 \mathrm{~cm}-1$ & $\mathrm{C}-\mathrm{H}$ bending of lipids \\
\hline $1,580 \mathrm{~cm}-1$ & Cytochrome c \\
\hline $1,580-1700 \mathrm{~cm}-1$ & Amide: stretching vibration of $\mathrm{C}=\mathrm{O}$ \\
\hline 1,655 & $v(\mathrm{C}=\mathrm{C})$ cis double bond stretching mode \\
\hline 1,676 & $A \beta$ \\
\hline $1740 \mathrm{~cm}-1$ & Stretching vibration from $\mathrm{C}=\mathrm{O}$ in lipid, $\mathrm{A}$ shift to higher wavenumbers for longer chain length fatty acids \\
\hline $2,852 \mathrm{~cm}-1$ & $\mathrm{CH} 2$ symmetric stretching (lipids) \\
\hline $2,875 \mathrm{~cm}-1$ & $\mathrm{CH} 2$ asymmetric stretching (lipids, proteins) \\
\hline 2,920-2,937 cm-1 & CH3 symmetric stretching (lipids) \\
\hline $2,959 \mathrm{~cm}-1$ & $\mathrm{CH} 3$ asymmetric stretching (lipids, proteins) \\
\hline $3,005 \mathrm{~cm}-1$ & Olefinic = $\mathrm{CH}$ stretching (unsaturated lipids, cholesterol esters) \\
\hline
\end{tabular}

Compared with the mature oocyte, germarium and developing follicles showed relatively high intensities at $780 \mathrm{~cm}^{-1}$, $1,000 \mathrm{~cm}^{-1}$, and $1,580 \mathrm{~cm}^{-1}$ (Figure 1B). This could be due to a higher content of nucleic acids, proteins, or Cytochrome c. In addition, the Raman signals observed at these three positions showed a gradually increasing intensity along with the maturation of the follicle. Furthermore, we found the intensity of these Raman signals peaked at stage 8 follicles and then reduced in mature eggs. Similarly, accompanied by follicle maturation, the intensity of amide III broad band increased (from germarium to the developing follicle stage 1, stage 3, stage 5 , stage 8 ), but there was a shape remodeling of amide III in the last stage of oogenesis (stage 14), which is a classic lipidenriched shape (Figures 1B,D). Consistently, the Raman bands present in the high wavenumber show a dramatically high intensity at $2,852 \mathrm{~cm}^{-1}$ in stage 14 oocytes, which was assigned to symmetric vibrations of the $\mathrm{CH}_{2}$ groups present in lipids (Figures 1C,E). The lipid accumulation of stage 14 detected by Raman spectra is consistent with the Nile red staining results presented by the previous studies (Parra-Peralbo and Culi, 2011; Sieber and Spradling, 2015).

The peak at 2,937 $\mathrm{cm}^{-1}$ was mainly due to the $\mathrm{CH}$ stretching mode of $\mathrm{CH}_{3}$ groups from proteins. It has a similar profile of proteins and lipids for both germarium and the developing follicles (stage 1 , stage 3 , stage 5 , stage 8 ). The protein peak position of the mature oocytes was left-shifted as depicted in Figures 1C,E. The shift of the peak was possibly due to the large amount of yolk proteins interacting with lipids in a specific way, or the proteins being modified by lipids at this mature stage. However, further investigation is necessary to clarify this.

\section{DO-SRS Imaging of Metabolic Activity of Drosophila Ovariole During Aging}

The female flies continuously produce hundreds of eggs throughout their lifespan (Rogina et al., 2007). The continued oocyte production requires consecutive division of the stem cells. The egg production is dramatically decreased during female aging, indicating a significant compromise in the rate of stem cell division (Ren et al., 2017; Dipali et al., 2019; Armstrong, 2020). Both autonomous signals from a defect in the stem cells and the nonautonomous signals sent to the germ stem cells from the surrounding niche can contribute to replicative senescence (Narbonne, 2018; Sênos Demarco and Jones, 2019). It has been suggested that the nutrient status of Drosophila determines the ovarian function, as enormous energy is required to fuel the oogenesis (Pritchett et al., 2009; Jeong et al., 2019; Armstrong, 2020). The aged flies have impaired physical activity and reduced digestive function, which suggests that malnutrition may contribute to ovarian senescence during aging. In addition, some studies have shown the morphology and dynamics of mitochondria changing during ovarian aging (May-Panloup et al., 2016; Garcez et al., 2020). However, the direct evidence of subcellular metabolic activity changes during ovarian aging has not been revealed. 

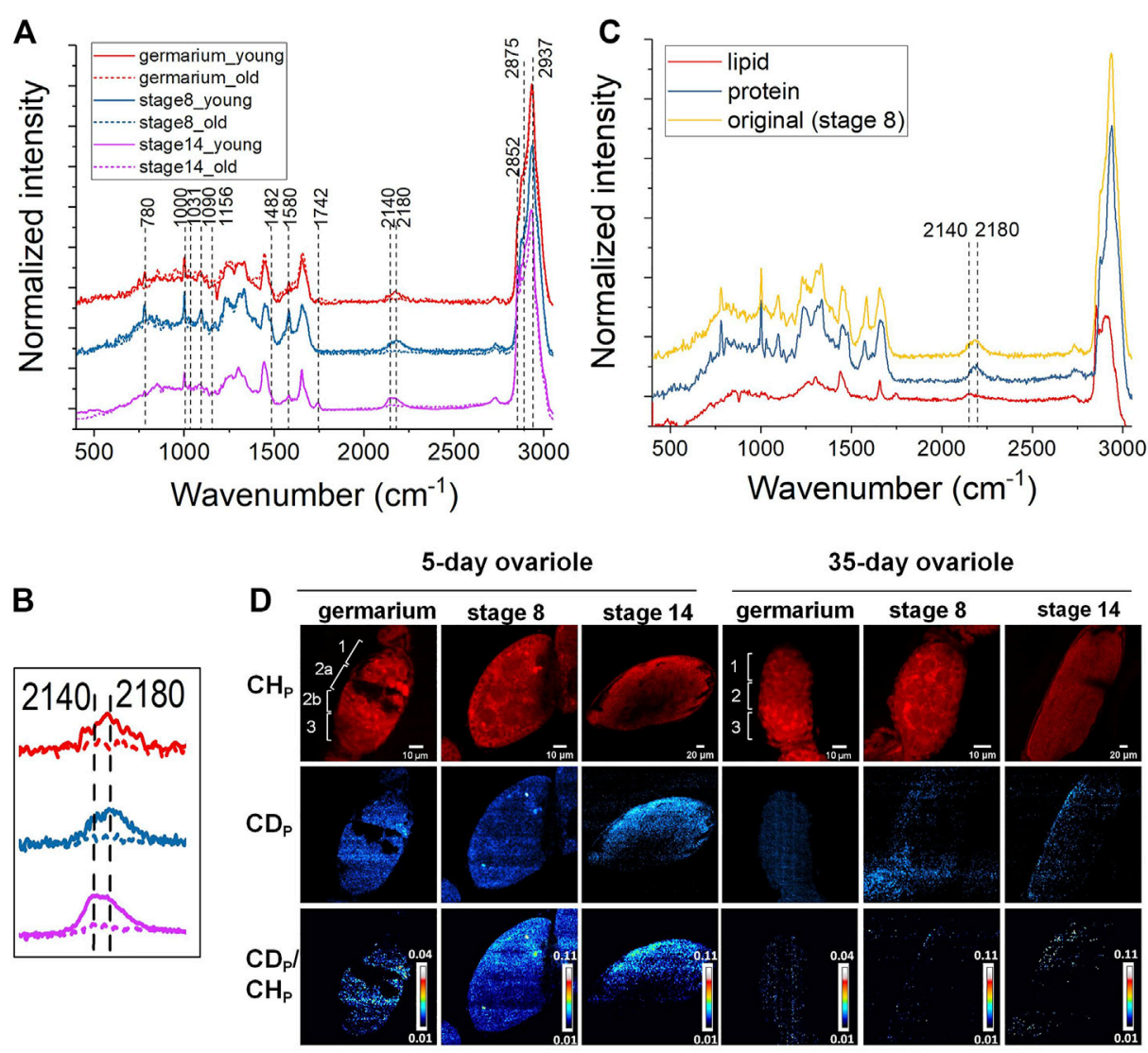

FIGURE 2 | DO-Raman spectra and DO-SRS imaging of changes in lipid and protein metabolic activities in aging Drosophila ovary. (A) Averaged spectra of follicles at different developmental stages in 5- (solid line) and 35-day (dashed line) old flies $(n=10)$. The flies were treated with $20 \%$ D2O for 5 days. A decent CD signal was shown in the cell silent region. The CD intensity was greatly reduced in 35-day-old flies. (B) The C-D bond peaked at lower wavenumbers $\left(\sim 2,140 \mathrm{~cm}^{-1}\right)$ resembled newly synthesized lipids at stage 14, while the C-D peak acquired from the early developing follicles toward a higher wavenumber (around 2,180 $\mathrm{cm}^{-1}$ ) was mainly assigned to the newly synthesized proteins. Both CD proteins and lipids were reduced in the 35-day-old flies (dashed lines). (C) Normalized Raman spectra of follicles before (yellow) and after being treated with protease $\mathrm{K}$ (red) or washed with methanol (blue), respectively. Compared with the CD peak shown in the untreated spectrum (yellow), CD protein (blue) and lipid (red) peak positions were confirmed by dissolving lipids with methanol that abolished the peak at 2,140 $\mathrm{cm}^{-1}$ and removing proteins by proteinase $\mathrm{K}$ treatment that eliminated the peak at 2,180 $\mathrm{cm}^{-1}$, respectively. (D) DO-SRS imaging of protein metabolic dynamic in young and old Drosophila ovariole. DO-SRS images at 2,180 $\mathrm{cm}^{-1}$ displayed the subcellular localization of CD (newly synthesized) protein. In the same region of interest, SRS images at 2,937 $\mathrm{cm}^{-1}$ demonstrated the $\mathrm{CH}$ (total) proteins. The ratiometric images of $\mathrm{CD}_{p} / \mathrm{CH}_{\mathrm{p}}$ were generated to show the location of newly synthesized proteins. The scale bars in germarium and stage 8 are $10 \mu \mathrm{m}$, and in stage 14 is $20 \mu \mathrm{m}$.

To address this, we applied DO-SRS imaging to visualize newly synthesized lipids and proteins and quantify their turnover rates in aging ovaries. Flies (0-day and 30-day after eclosion) were treated with $20 \% \mathrm{D}_{2} \mathrm{O}$ for 5 days to obtain a detectable incorporation of $\mathrm{CD}$ signal for Raman imaging. After a 5-day labeling, decent $\mathrm{CD}$ signals were detected at each developmental stage (germarium, stage 1 , stage 3 , stage 5 , stage 8 , and stage 14) of the ovarioles in 5-day-old females. We acquired spectra from the fingerprint region (Figure 2A, Supplementary Figure S1A) and $\mathrm{C}-\mathrm{H}$ region (Figure 2A, Supplementary Figure S1B), and observed proteins and lipids were dominated in developing follicles and mature oocytes, respectively, which were consistent with label-free Raman spectra that we collected previously. The C-D bond peak at $2,140 \mathrm{~cm}^{-1}$ resembled the newly synthesized lipids at stage 14 , while the C-D peak acquired from the early developing follicles toward a higher wavenumber (around $2,180 \mathrm{~cm}^{-1}$ ) was mainly from the newly synthesized proteins (Figures 2A,B). The peak positions of $\mathrm{CD}$ proteins/lipids are consistent with that in fat body tissues and other biological systems as reported previously (Li et al., 2021; Singh and Keiderling, 1981). Furthermore, we reconfirmed these results by dissolving lipids using methanol that abolished the peak at $2,140 \mathrm{~cm}^{-1}$, and removing proteins by proteinase $\mathrm{K}$ treatment that eliminated the peak at $2,180 \mathrm{~cm}^{-1}$ (Figure 2C), respectively, which were consistent with our previous observations in mice (Shi et al., 2018).

Compared with the 5-day-old females, the CD signals from 35day-old flies were largely reduced (Figures 2A,B, Supplementary Figure S2). This indicates that the amount of newly synthesized lipids (Supplementary Figures S2A, B, C) and proteins (Supplementary Figures S2D, E, F) was dramatically deceased in old ovaries. In the same region of interest, the SRS images of $\mathrm{CH}$ lipids and $\mathrm{CH}$ proteins were acquired at $2,852 \mathrm{~cm}^{-1}$ and $2,937 \mathrm{~cm}^{-1}$, respectively (Figure 2D, Supplementary Figure S1C). 
For quantification, $\mathrm{CD} / \mathrm{CH}$ was used as a ratiometric indicator for the amount of newly synthesized macromolecules normalized against variations among individuals and heterogeneity within the same tissue. From the results displayed in Figure 2D, Supplementary Figure S1C, we first visualized protein and lipid synthesis in Drosophila ovariole simultaneously during germline development and resolved their different metabolic dynamics. Previous studies reported that there was a large amount of lipids deposited inside the mature oocytes (Dunning et al., 2014; Ishigaki et al., 2017), however, it is unclear whether there is any difference between protein and lipid accumulation among oocytes and other earlier developing stages. In addition, there is no study on the metabolic activity changes of ovary during Drosophila aging. To better describe the distribution of different cell types in the germarium, it is divided into 4 discrete regions (regions 1, 2a, 2b, and 3) based on the overall morphology shown in the protein channel $\left(2,937 \mathrm{~cm}^{-1}\right)$ and according to the developmental stage of the nascent germline cyst and its derived oocyte reported in the literatures. Region 1 of the germarium contains the germ stem cell (GSC) niche and germline cysts of 2, 4, or 8 cells. Region 2a contains 16 cell germline cysts in which two pro-oocytes are determined. In region $2 \mathrm{~b}$, the nurse cells and oocyte are specified. As the cyst enters into region 3, the nurse cells are enlarged and the oocyte adheres to the posterior, and they are wrapped by surrounding follicle cells.

We found that 5-day-old flies showed active protein and lipid syntheses inside the ovariole at all the stages (Figure 2D, Supplementary Figure S1C). Earlier developing stages showed higher levels of protein synthesis, while no obvious difference of turnover rates among different cell types was observed. Our results demonstrated that in the young ovary where protein and lipid synthesis continuously increased throughout the germline development and reached the highest level in mature oocytes. Lipid and protein metabolism also showed different agerelated dynamics in Drosophila ovary, consistent with the Raman spectra. The overall protein and lipid synthesis rate reduced dramatically in 35-day-old flies as compared with 5-day-old ones, indicating a decline in metabolic activity during aging.

\section{SRS Imaging of Lipid Subtype Distribution in Aging Drosophila Ovariole}

The subcellular resolution and the molecular specificity of SRS microscopy also enabled us to differentiate distinct spatial patterns of different lipid subtypes. Previous studies reported that the $2,875 \mathrm{~cm}^{-1} / 2,852 \mathrm{~cm}^{-1}$ ratio can be used as an indicator for both conformational state and lateral packing of lipids (Choe et al., 2016; Uematsu and Shimizu, 2021). High values of this ratio have been associated with a compact organization and a solid phase of lipids, which is usually related to high content of saturated lipids (Matthews et al., 2010; Uematsu and Shimizu, 2021). The ratio of $3,005 \mathrm{~cm}^{-1} / 2,852 \mathrm{~cm}^{-1}$ corresponds to the relative level of unsaturated lipid to total lipids in the tissue (Toledo et al., 2016). To understand how lipid subtypes change during ovarian aging at the subcellular level, we applied label-free SRS imaging at $2,875 \mathrm{~cm}^{-1}, 3,005 \mathrm{~cm}^{-1}$, and $2,852 \mathrm{~cm}^{-1}$, and generated ratiometric images to map the distribution of saturated and unsaturated lipids in three representative stages, the germarium, stage 8 , and stage 14 .

As shown in Figure $\mathbf{3 A}$, the lipids were mainly localized at regions $1,2 \mathrm{~b}$, and 3 in the germarium of 5-day ovary. A cleft was clearly observed from the SRS images between regions 1 and $2 b$, where region $2 \mathrm{a}$ containing developing cysts was localized. Almost no SRS signals could be detected inside the cleft except some membrane structures, indicating that the macromolecular constitutions are different among these regions. However, the cleft disappeared in 35-day-old fly ovary, suggesting that chemical or structural changes happened in old females. Our SRS ratiometric images showed higher saturated lipid content in regions 1 and $2 \mathrm{a}$ of the germariums from young females, but the lipid content was largely reduced in the germariums of 35-day-old flies. Saturated lipids in region $2 \mathrm{~b}$ were mainly localized in the lipid droplets inside the nurse cells from 5-day-old flies, which were condensed to the bar-shaped structures in the 35-day-old flies. The bar-shaped structure looks like an intercellular bridge between the adjacent cells, reminiscent of fusome that is localized in the developing cells of germline cysts. The fusome is an organelle conserved from invertebrates to mammals, which plays an important role in the synchronization of the cell cycle and controlling of the gamete quality by sharing substances between cells (Deng and Lin, 1997). Previous studies revealed that the fusome originated from endoplasmic reticulum related membrane vesicles and is associated with many proteins and organelles (Deng and Lin, 1997; Hsu et al., 2008; Hinnant et al., 2020). However, our images indicate an abundant amount of saturated lipids in this bar-shaped structure. Further study is necessary to determine this structure.

Similar to saturated lipids, the unsaturated lipids were largely reduced in region 1 of the germarium (Figure 3B), indicating that the total lipids were dramatically decreased in germ stem cell niche during aging. However, unsaturated lipids tend to be accumulated in region 3 of the old flies compared with young ones. Consistently, this phenomenon was also observed in stage 8 follicles of the old flies. In old flies, the amount of unsaturated lipids was increased in germ cells (nurse cells and oocytes) but was reduced in the surrounding follicle cells (somatic cells). This lipid distribution is different from that in the younger ones, which shows both types of lipids being localized in the outer-layer follicle cells (somatic cells) as well as inside the germ cells (germ cells). As the nutrition trafficking between follicle cells, nurse cells, and oocytes maintains the lipid homeostasis between the somatic and germ cells (Shkolnik et al., 2011; Zhang et al., 2019a; Zhang et al., 2019b), the decreased lipid level in follicle cells may indicate the disruption of molecular trafficking between these cells, leading to reduced number and quality of eggs.

Altogether, our label-free SRS images showed that the developing follicles in the 35-day-old flies had lower lipid contents and disrupted lipid distributions compared with the 5 -day-old files. Other studies suggest that the development of oocyte depends on the nutritional support from nurse and somatic cells in the earlier stages (Bogliolo et al., 2013; Bertevello et al., 2020). Our Raman spectral data also suggest 
A

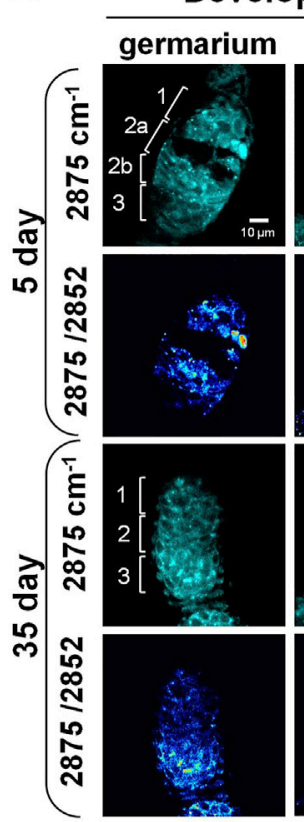

Developmental stages
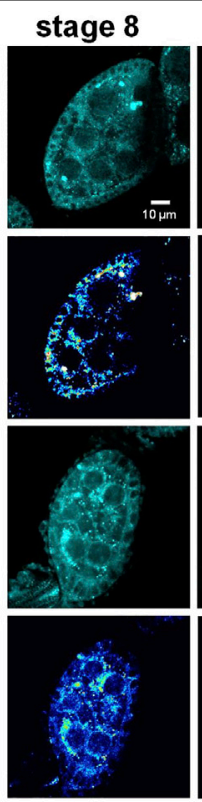

stage 14
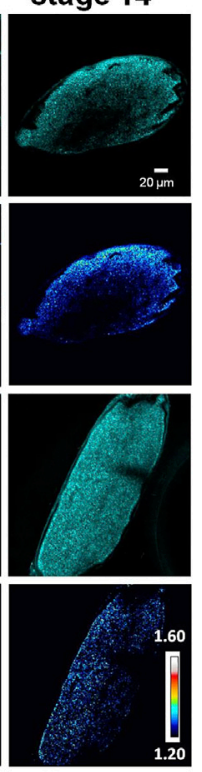

B

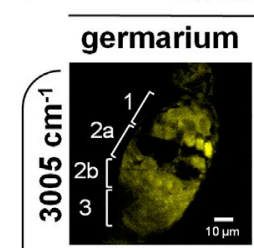

Developmental stages
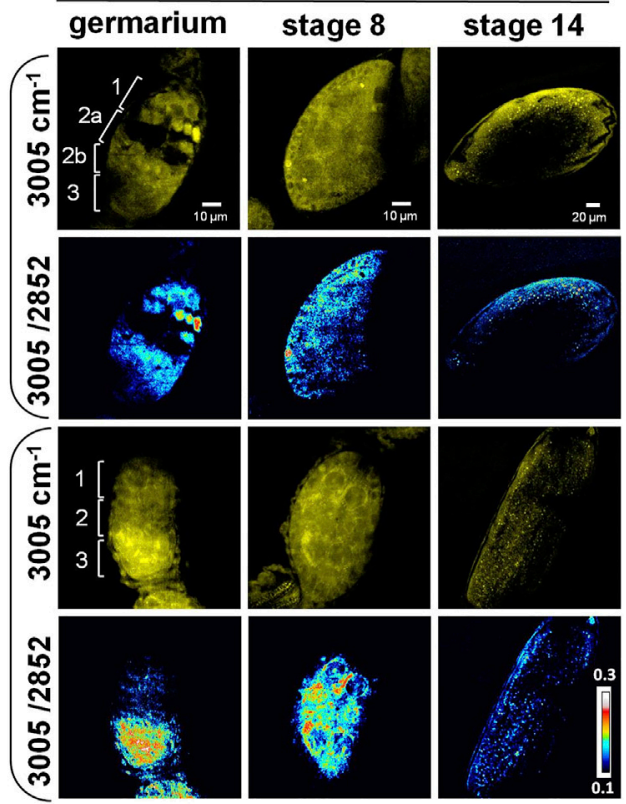

FIGURE 3 | SRS imaging of lipid subtypes' change in developing follicles of aging Drosophila. (A) SRS imaging at $2,875 \mathrm{~cm}^{-1}$ of 5 - and $35-$ day ovaries. The ratiometric images of $2,875 \mathrm{~cm}^{-1} / 2,852 \mathrm{~cm}^{-1}$ were used to evaluate the concentration and distribution of saturated lipids. The images showed higher saturated lipid content in regions 1 and $2 a$ of the germariums in young flies, but it was reduced in the germariums of 35 -day-old flies. Saturated lipids in region $2 \mathrm{~b}$ were mainly localized in the lipid droplets inside the nurse cells of 5-day-old flies, but they were condensed to the bar-shaped structures in 35-day-old flies. At stage 8, saturated lipid was visualized in the cytoplasm of germ cells in both young and old files, but it was reduced in the surrounding follicle cells in old files. The level of saturated lipids at stage 14 was reduced in old flies compared with young ones. Scale bar, $10 \mu \mathrm{m}$ in germarium and stage 8 , and $20 \mu \mathrm{m}$ stage 14 . (B) SRS imaging at 3,005 $\mathrm{cm}^{-1}$ of 5 - and 35 -day ovaries. The ratiometric images of $3,005 \mathrm{~cm}^{-1} / 2,852 \mathrm{~cm}^{-1}$ were used to evaluate the concentration and distribution of unsaturated lipids. Unsaturated lipids were largely reduced in region 1 of the germarium during fly aging. However, they tended to be accumulated in region 3 in old flies, where germ cells were localized. The distribution of unsaturated lipids is consistent in repeated experiments for stage 8 follicles in old flies. Compared with the young flies, the content of unsaturated lipids in old files germ cells (nurse cells and oocytes) was increased, but it was reduced in the surrounding follicle cells (somatic cells). The level of unsaturated lipids at stage 14 was reduced in old flies compared with the young ones. Scale bar, $10 \mu \mathrm{m}$ in germarium and stage 8, and $20 \mu \mathrm{m}$ stage 14.

the molecular remodeling toward lipid accumulation happening in the last stages of oogenesis. Combined with the changes in lipid hemostasis observed from SRS imaging, we hypothesized that lipid metabolism also changed in mature eggs.

This is supported by our ratiometric images that the number of lipid (both saturated and unsaturated lipids) enriched particles in eggs from 5-day-old ovaries was significantly reduced in 35day-old flies. The morphology of eggs from these two age groups also showed differences as well. The eggs generated from 5-dayold females were plump, whereas the 35-day-old females appeared slimmer, suggesting the decrease in biomass in the eggs from old females.

\section{SRS Imaging of Cytochrome c Distribution in Aging Drosophila Ovary}

As previously mentioned, the Raman peak at $1,580 \mathrm{~cm}^{-1}$ was assigned to Cytochrome $\mathrm{c}$ or carotenoids. To identify the molecule, we treated the ovary with methanol that removed carotenoids. The peak still existed after the treatment (Figure 2C), indicating it was from the porphyrin ring of Cytochrome c (Kumamoto et al., 2018; Hniopek et al., 2021).
Using SRS microscopy, we next imaged Cytochrome $\mathrm{c}$ in developing germ cells to probe its change during aging. Among the stages that we observed, the signal from $1,580 \mathrm{~cm}^{-1}$ mainly appeared in the germarium and stage 8 , but not at stage 14 in both young and old flies (Figure 4). This is consistent with the Raman spectra we measured where the $1,580 \mathrm{~cm}^{-1}$ peak existed only in the developing follicles but not in the mature oocytes. To semi-quantitatively analyze subcellular level of Cytochrome $\mathrm{c}$ between young and old flies, we normalized the intensity of $1,580 \mathrm{~cm}^{-1}$ to the whole protein level at 2,937 $\mathrm{cm}^{-1}$. As shown in Figure 4, in 5-day young flies germarium, Cytochrome $c$ exist in germ stem cell niche and the developing cysts, while in the old flies, the total level of Cytochrome $\mathrm{c}$ was decreased, especially in region 1 where germ stem cell niche was localized. At stage 8, Cytochrome c showed a clear mitochondrial pattern in the nurse cells in both young and old ovaries, which is consistent with its in situ localization to the intermembrane space of these organelles. In the young ovary, Cytochrome $c$ was evenly distributed in the cytoplasm of nurse and follicle cells. Interestingly, Cytochrome c signal was upregulated in the nurse cells and reduced in the follicle cells in old ovaries. 


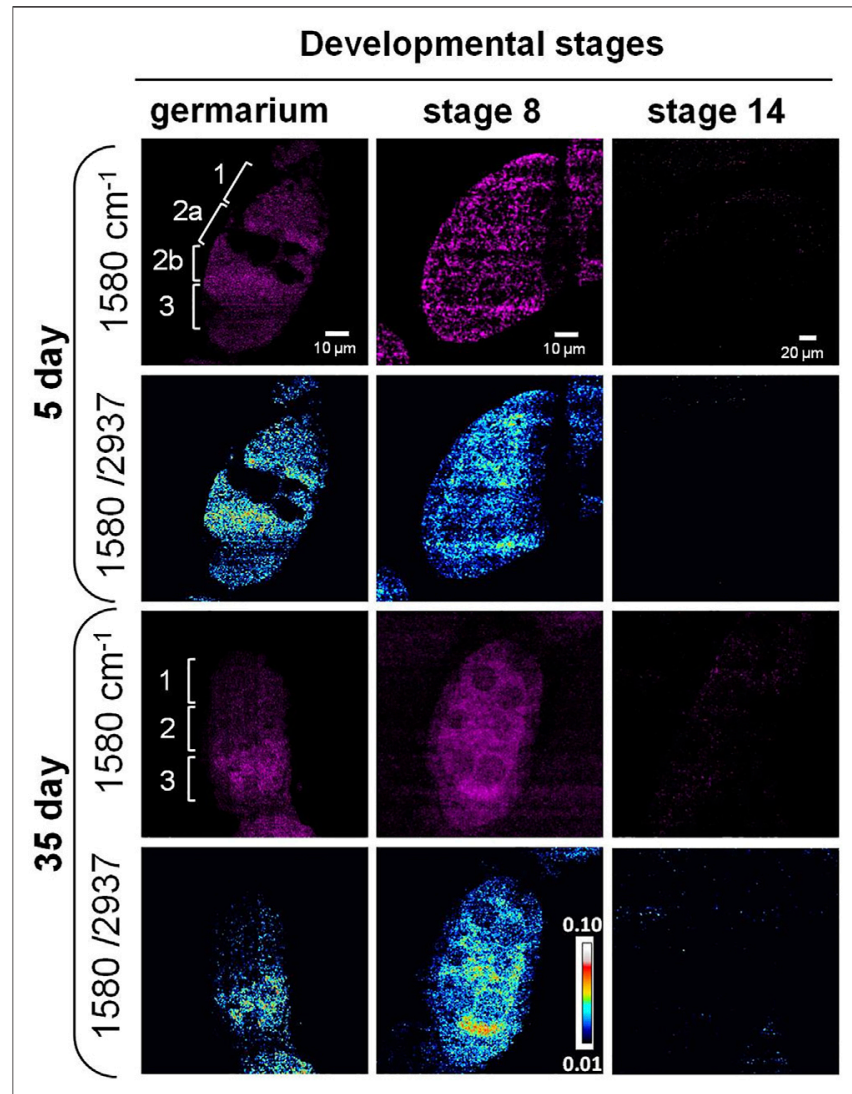

FIGURE 4 | SRS imaging of Cytochrome c distribution in aging Drosophila ovary. SRS imaging at $1,580 \mathrm{~cm}^{-1}$ in 5 - and 35 -day ovaries. The ratiometric images of $1,580 \mathrm{~cm}^{-1} / 2,937 \mathrm{~cm}^{-1}$ were used to evaluate the concentration and distribution of Cytochrome c. In day 5 germarium,

Cytochrome $\mathrm{c}$ was detected in the germ stem cell niche and the developing cysts. However, in old flies, the overall level of Cytochrome c was decreased, especially in region 1 where germ stem cell niche was localized. At stage 8, Cytochrome c showed a clear mitochondrial pattern in the nurse cells in both young and old ovaries, which is consistent with its in situ localization to the intermembrane space of these organelles. In the young ovary, Cytochrome $c$ was evenly distributed in the cytoplasm of nurse and follicle cells at stage 8 , while its signal level was upregulated in the nurse cells and reduced in the follicle cells in old ovaries. Inside the nurse cells, Cytochrome c was more evenly distributed in young flies but more condensed in old flies. Scale bar, $10 \mu \mathrm{m}$ in germarium and stage 8, and $20 \mu \mathrm{m}$ stage 14 .

Apart from the signal level changes of Cytochrome $c$, the signal distribution also showed differences between young and old flies. Cytochrome $\mathrm{c}$ was more evenly distributed in young flies but more condensed in old flies, suggesting the change in mitochondrial structure with aging. It has been reported that the fusion and fission dynamics of mitochondrial are changed during aging in Drosophila ovary (Ishihara et al., 2009; Sênos Demarco et al., 2019; Sênos Demarco and Jones, 2019), and altered mitochondrial biogenesis happens during oogenesis in other model systems (Dunning et al., 2014; Garcez et al., 2020). The change in Cytochrome $\mathrm{c}$ during aging may lead to altered mitochondrial dynamics (Varkey et al., 1999). Our results suggest that SRS imaging can be used as a powerful tool to monitor mitochondrial dynamics and function in situ.
Cytochrome c release is an important event in the intrinsic pathway of apoptosis. In the late-stage egg chambers, nurse cells transfer their cytoplasmic contents to the developing oocytes and undergo apoptotic cell death. Cytochrome $\mathrm{c}$ is released from the mitochondria and can result in the activation of caspases (Martin and Baehrecke, 2004; Pritchett et al., 2009). Active caspases can be detected in region 2 of the germarium using an anti-active caspase-3 antibody, and mutants lacking the effector caspase show a reduced level of DNA fragmentation and autophagy in region 2 when compared with the wild type. Studies also showed high levels of caspase-mediated cell death in mid-oogenesis (Peterson et al., 2003; Mazzalupo and Cooley, 2006). Further functional studies are needed to elucidate the relationship between aging-dependent Cytochrome $c$ change and ovary function.

\section{DISCUSSION}

The development of the Drosophila oocytes is a very complex process where it begins from a syncytium that is formed by 16 sister cells derived from four rounds of incomplete division of a single germ cell. These 16 cells share the same cytoplasm. Only one of them will become the oocyte, while the remaining 15 cells differentiate to nurse cells, which fuel the oocyte with nutrients and cytoplasmic components (Doherty et al., 2021). This means that the polarization of the cyst cytoplasm and membrane are involved in the selection of the oocyte (Theurkauf, 1994). The polarization of the oocyte is intimately associated with the establishment of the body axes of the fly and the following embryo development (Huynh and St Johnston, 2004). All these processes depend on reciprocal interactions between germ cells and their somatic niche (Bertevello et al., 2020). Many factors and signaling pathways are involved in the processes of oocyte determination (Zimon et al., 2006; Perrimon et al., 2012). One of them is Notch signaling pathway that plays an important role in controlling cell proliferation and differentiation through cell-cell interaction (Zimon et al., 2006). However, whether and how lipid metabolism affects the cell determination remains unclear. Our label-free SRS imaging results show that different types of cells have diverse lipid profiles in the germ stem cell niche as well as the developing follicles, and the level and distribution of these lipid components are changed during development and aging (Figures 3A,B).

During Drosophila aging the division of stem cells reduces dramatically, which is coincident with decreased egg production and fly infertility (Zimon et al., 2006; Shi et al., 2016; Dipali et al., 2019). However, it is still unclear if this reproductive defect is cell autonomous or nonautonomous. Apoptosis and resorption of developing egg chambers could also lead to the decrease in fertility (Drummond-Barbosa and Spradling, 2001). If the early aging stages of these events could be measured, it would provide valuable information to prevent or slow down the decline processes of the ovary. Methods have been developed to genetically study the survival of stem cells, division rate, and function during aging in adult Drosophila. Studies indicated 
cellular stresses such as oxidative and heat shock, endocrine and insulin signaling, epigenetic modification and chromatin structure, and metabolic homeostasis as major factors involved in the reproduction maintenances (Hsu et al., 2008; Bogliolo et al., 2013; Mok et al., 2016; Shi et al., 2016; Jeong et al., 2019; Sasaki et al., 2019). This indicates that the internal and external factors work together to determine the ovary aging processes. In our study, DO-SRS was used to sensitively monitor the metabolic activity change in developing follicles during aging (Figure 2, Supplementary Figure S1 and Supplementary Figure S2).

Cytochrome c, which is a protein important for mitochondrial function and commonly used as a mitochondrial marker (Schägger, 2002), could be detected by Raman and SRS microscopy. Previous electron microscopy (EM) (Garcez et al., 2020) and immunostaining fluorescence studies have documented that GSCs in region 1 of germarium have a predominantly small punctate mitochondria, and that mitochondria progressively becomes more aggregated in regions $2 \mathrm{~b}$ and 3 , consistent with an increase in mitochondria fusion (Zhang et al., 2019a; Zhang et al., 2019b; Sênos Demarco et al., 2019; Amartuvshin et al., 2020; Chen et al., 2003). This increase in mitochondria fusion along with cell differentiation suggests that mitochondrial dynamics may play a role in regulating cell fate. Another study showed that mitochondrial dynamics also changes during the aging process with an increase in fission and decrease in fusion in Drosophila (Amartuvshin et al., 2020). Our results consistently show that the aging ovarioles have a condensed signal of Cytochrome $\mathrm{c}$, which may be due to the dynamics change of the mitochondria (Figure 4). We also detected that the level of Cytochrome $\mathrm{c}$ was reduced in the developing follicles in aged flies (Figure 4). As Cytochrome $\mathrm{c}$ is an essential component of the electron transport chain, reduction of Cytochrome $\mathrm{c}$ indicates that the mitochondrial function may be compromised during aging in the ovary. Our results show that unsaturated lipids and Cytochrome $c$ were accumulated simultaneously in egg chambers from old flies, especially in stage 8 (Figures $3 \mathbf{B}, 4$ ). Previous studies demonstrated some types of lipids could induce cell apoptosis or non-apoptosis-dependent cell death (Knoblich, 2008; Pritchett et al., 2009; Park et al., 2018; Liang et al., 2020). Further studies are necessary to investigate if the interplay between unsaturated lipids and Cytochrome $\mathrm{c}$ is involved in aging-dependent malfunction of ovary.

For the first time, using label-free and $\mathrm{D}_{2} \mathrm{O}$-probed Raman and SRS imaging we revealed lipid metabolism in the ovary during Drosophila aging (Figures $\mathbf{1 B}-\mathbf{E}$ and Figure 2A). For future studies, it will be interesting to understand how these metabolic changes are related to the reproductive decline in Drosophila, the causes of such decline, and whether these changes will be conserved among different species. To address these questions, genetic or diet manipulation can be potentially used to identify new genes or food components that can modulate the reproductive life span. Genetic studies have begun to uncover genes regulating reproductive life span (Rose and Charlesworth, 1981; Helfand and Rogina, 2003; Partridge et al., 2005). The high glucose and protein-enriched foods were reported to change (May et al., 2015; Zanco et al., 2021) the reproductive status of Drosophila, even though the underlying mechanisms are still unclear. DO-Raman/SRS demonstrates a broad application in monitoring metabolic changes in tissues and cell in situ, toward unraveling the underlying mechanisms between metabolism, reproduction, and aging.

\section{MATERIALS AND METHODS}

\section{Fly Stocks}

Wild type ( $w^{1118}$ stock \#5905) were originally obtained from the Bloomington Stock Center and have been maintained in the lab for several generations.

\section{$\mathrm{D}_{2} \mathrm{O}$-Labeling Experiments}

The metabolic activity changes of wild-type flies at different ages were labeled by transferring the 0 -day, and 30-day (after eclosion) female adult flies to the $20 \% \mathrm{D}_{2} \mathrm{O}$ labeled corresponding food conditions for 5 days, then the 5-day, and 35-day aged flies were sacrificed, and ovaries were dissected and subjected to Raman measurements and SRS imaging.

\section{Drosophila Sample Preparation for Raman and SRS Microscopy}

Ovary tissues were dissected in PBS and fixed in 4\% formaldehyde for $30 \mathrm{~min}$ at room temperature (RT). After fixation, tissues were washed four times with PBS in glass wells. Tissues were then sandwiched between a cover slide and bottom slide with PBS solution. To prevent the tissue drying, nail polish was used to seal the surrounding of cover slides.

\section{Spontaneous Raman Spectroscopy}

Raman spectra of all the tissue samples were measured by a Raman spectrometer connected to a confocal Raman microscope (XploRA PLUS, Horiba). A $532 \mathrm{~nm}$ diode line focus laser $(\sim 40 \mathrm{~mW}$ at the sample) was focused on the cells with the help of a $\times 100$ objective (MPLN $\times 100$, Olympus). The laser power on the sample was optimized to avoid any damage to the cells. A cooled charge coupled device (CCD) detector fitted to a 2,400 grooves $/ \mathrm{mm}$ grating spectrometer was used to detect the signal. Spectra were collected at $60 \mathrm{~s}$ acquisitions with an accumulation of 2. The background spectra were taken for each tissue point at the same focus plane and were subtracted from original spectrum immediately. All ratio calculations were carried out on the raw data before any normalization or baseline correction steps. Peaks were normalized to the phenylalanine peak at $1,003 \mathrm{~cm}^{-1}$. The instrumental calibration was verified using the silicon line at $520 \mathrm{~cm}^{-1}$. The observed data were processed and analyzed using Prism software (Origin Lab Corporation, Northampton, MA).

\section{Stimulated Raman Scattering Microscopy}

An upright laser-scanning microscope (DIY multiphoton, Olympus) with a $\times 25$ water objective (XLPLN, WMP2, $1.05 \mathrm{NA}$, Olympus) was applied for near-IR throughput. Synchronized pulsed pump beam (tunable $720-990 \mathrm{~nm}$ wavelength, 5-6 ps pulse width, and $80 \mathrm{MHz}$ repetition rate) and Stokes (wavelength at $1032 \mathrm{~nm}$, 6 ps pulse width, and $80 \mathrm{MHz}$ repetition rate) were supplied by a 
picoEmerald system (Applied Physics and Electronics) and coupled into the microscope. The pump and Stokes beams were collected in transmission by a high NA oil condenser (1.4 NA). A high O. D. shortpass filter (950 nm, Thorlabs) was used that would completely block the Stokes beam and transmit the pump beam only onto a $\mathrm{Si}$ photodiode for detecting the stimulated Raman loss signal. The output current from the photodiode was terminated, filtered, and demodulated by a lock-in amplifier at $20 \mathrm{MHz}$. The demodulated signal was fed into the FV3000 software module FV-OSR (Olympus) to form image during laser scanning. All images obtained were $512 \times$ 512 pixels, with a dwell time of $80 \mu \mathrm{s}$ and an imaging speed of $\sim 23 \mathrm{~s}$ per image. A background image was acquired at $1900 \mathrm{~cm}^{-1}$ and subtracted from all SRS images using Fiji (ImageJ).

\section{Statistical Analysis}

Student $t$-test was performed for statistical analysis using GraphPad Prism software. Ratio data were analyzed from raw intensity values without baseline correction and normalization.

\section{DATA AVAILABILITY STATEMENT}

The original contributions presented in the study are included in the article/Supplementary Material, further inquiries can be directed to the corresponding author.

\section{ETHICS STATEMENT}

The animal study was reviewed and approved by the UCSD.

\section{AUTHOR CONTRIBUTIONS}

YL and LS conceived the concept, designed the experiments. YL conducted the experiments, analyzed the data, making figures,

\section{REFERENCES}

Amartuvshin, O., Lin, C. H., Hsu, S. C., Kao, S. H., Chen, A., Tang, W. C., et al. (2020). Aging Shifts Mitochondrial Dynamics toward Fission to Promote Germline Stem Cell Loss. Aging Cell 19, e13191. doi:10.1111/acel.13191

Armstrong, A. R. (2020). Drosophila melanogaster as a Model for Nutrient Regulation of Ovarian Function. Reproduction 159, R69-R82. doi:10.1530/ REP-18-0593

Baddela, V. S., Sharma, A., and Vanselow, J. (2020). Non-esterified Fatty Acids in the Ovary: Friends or Foes? Reprod. Biol. Endocrinol. 18, 60. doi:10.1186/ s12958-020-00617-9

Bagheri, P., Hoang, K., Fung, A. A., Hussain, S., and Shi, L. (2021). Visualizing Cancer Cell Metabolic Dynamics Regulated with Aromatic Amino Acids Using Do-SRS and 2PEF Microscopy. Front. Mol. Biosci. 8, 779702. doi:10.3389/fmolb.2021.779702

Berry, D., Mader, E., Lee, T. K., Woebken, D., Wang, Y., Zhu, D., et al. (2015). Tracking Heavy Water (D2O) Incorporation for Identifying and Sorting Active Microbial Cells. Proc. Natl. Acad. Sci. USA 112, E194-E203. doi:10.1073/ pnas. 1420406112

Bertevello, P. S., Teixeira-Gomes, A.-P., Labas, V., Cordeiro, L., Blache, M.-C., Papillier, P., et al. (2020). MALDI-TOF Mass Spectrometry Revealed Significant Lipid Variations in Follicular Fluid and Somatic Follicular Cells but Not in and performed statistical analyses with the help from $\mathrm{PC}, \mathrm{AZ}, \mathrm{PB}$, JH, AF, JYW, and LS. YL, PB, JYW, and LS wrote and revised the manuscript with the input from all other authors.

\section{FUNDING}

This work is partially supported by UCSD Startup funds, NIH U54 pilot grant 2U54CA132378-11A1, and Hellman Fellow Award.

\section{ACKNOWLEDGMENTS}

We thank Christian Metallo for helpful discussion.

\section{SUPPLEMENTARY MATERIAL}

The Supplementary Material for this article can be found online at: https://www.frontiersin.org/articles/10.3389/fragi.2021.819903/ full\#supplementary-material

Supplementary Figure S1 | DO-Raman and DO-SRS imaging of lipid metabolic activity changes in aging Drosophila ovary. The fingerprint region (A) and $\mathrm{CH}$ stretching region (B) of the Raman spectra of follicles at different developmental stages in 5- and 35-day flies. were enlarged to show the molecular bond difference between young and old flies. (C) DO-SRS imaging of CD lipids (newly-synthesized) at $2140 \mathrm{~cm}^{-1}$. In the same region of interest, SRS images of $\mathrm{CH}$ lipids (total lipids) were acquired at $2852 \mathrm{~cm}^{-1}$. The ratiometric images of $C D_{\llcorner} / C_{\llcorner}$were generated to show the location of newly-synthesized lipids. Scale bar, $10 \mu \mathrm{m}$ in germarium and stage 8 , and $20 \mu \mathrm{m}$ stage 14 .

Supplementary Figure S2 | Quantification of lipid and protein turnover rates in Drosophila ovary. At all stages, both lipid and protein turnover rates were significantly reduced in aging Drosophila. Raman spectra of germarium, stage 8 and stage 14 were collected from 5-day $(n=5)$ and 35-day $(n=5)$ Drosophila, respectively. Lipid $(\mathbf{A}, \mathbf{B}, \mathbf{C})$ and protein $(\mathbf{D}, \mathbf{E}, \mathbf{F})$ turnover rates were calculated and analyzed to compare the statistical significance between young and old flies. Results shown were mean \pm SD. ${ }^{\star \star \star \star}, p<0.0001$ using unpaired $t$-test.

Enclosed Oocytes between the Large Dominant and Small Subordinate Follicles in Bovine Ovary. Int. J. Mol. Sci. 21, 6661. doi:10.3390/ijms21186661

Bogliolo, L., Murrone, O., Di Emidio, G., Piccinini, M., Ariu, F., Ledda, S., et al. (2013). Raman Spectroscopy-Based Approach to Detect Aging-Related Oxidative Damage in the Mouse Oocyte. J. Assist. Reprod. Genet. 30, 877-882. doi:10.1007/s10815-013-0046-6

Chen, H., Detmer, S. A., Ewald, A. J., Griffin, E. E., Fraser, S. E., and Chan, D. C. (2003). Mitofusins Mfn1 and Mfn2 Coordinately Regulate Mitochondrial Fusion and Are Essential for Embryonic Development. J. Cel Biol 160, 189-200. doi:10.1083/jcb.200211046

Choe, C., Lademann, J., and Darvin, M. E. (2016). A Depth-dependent Profile of the Lipid Conformation and Lateral Packing Order of the Stratum Corneum In Vivo Measured Using Raman Microscopy. Analyst 141, 1981-1987. doi:10.1039/c5an02373d

Deng, W., and Lin, H. (1997). Spectrosomes and Fusomes Anchor Mitotic Spindles during Asymmetric Germ Cell Divisions and Facilitate the Formation of a Polarized Microtubule Array for Oocyte Specification inDrosophila. Develop. Biol. 189, 79-94. doi:10.1006/dbio.1997.8669

Dipali, S. S., Ferreira, C. R., Zhou, L. T., Pritchard, M. T., and Duncan, F. E. (2019). Histologic Analysis and Lipid Profiling Reveal Reproductive Age-Associated Changes in Peri-Ovarian Adipose Tissue. Reprod. Biol. Endocrinol. 17, 46. doi:10.1186/s12958-019-0487-6 
Doherty, C. A., Diegmiller, R., Kapasiawala, M., Gavis, E. R., and Shvartsman, S. Y. (2021). Coupled Oscillators Coordinate Collective Germline Growth. Develop. Cel 56, 860-870. e868. doi:10.1016/j.devcel.2021.02.015

Draga, R. O. P., Grimbergen, M. C. M., Vijverberg, P. L. M., Swol, C. F. P. v., Jonges, T. G. N., Kummer, J. A., et al. (2010). In Vivo Bladder Cancer Diagnosis by High-Volume Raman Spectroscopy. Anal. Chem. 82, 5993-5999. doi:10.1021/ ac100448p

Drummond-Barbosa, D., and Spradling, A. C. (2001). Stem Cells and Their Progeny Respond to Nutritional Changes during Drosophila Oogenesis. Develop. Biol. 231, 265-278. doi:10.1006/dbio.2000.0135

Duncan, F. E., and Gerton, J. L. (2018). Mammalian Oogenesis and Female Reproductive Aging. Aging 10, 162-163. doi:10.18632/aging.101381

Dunning, K. R., Russell, D. L., and Robker, R. L. (2014). Lipids and Oocyte Developmental Competence: the Role of Fatty Acids and $\beta$-oxidation. Reproduction 148, R15-R27. doi:10.1530/REP-13-0251

Ember, K. J. I., Hoeve, M. A., McAughtrie, S. L., Bergholt, M. S., Dwyer, B. J., Stevens, M. M., et al. (2017). Raman Spectroscopy and Regenerative Medicine: a Review. NPJ Regen. Med. 2, 12. doi:10.1038/s41536-017-0014-3

Garcez, M., Branco-Santos, J., Gracio, P. C., and Homem, C. C. F. (2020). Mitochondrial Dynamics in the Drosophila Ovary Regulates Germ Stem Cell Number, Cell Fate, and Female Fertility. Front. Cel Dev. Biol. 8, 596819. doi:10.3389/fcell.2020.596819

Ghita, A., Pascut, F. C., Mather, M., Sottile, V., and Notingher, I. (2012). Cytoplasmic RNA in Undifferentiated Neural Stem Cells: a Potential Labelfree Raman Spectral Marker for Assessing the Undifferentiated Status. Anal. Chem. 84, 3155-3162. doi:10.1021/ac202994e

Helfand, S. L., and Rogina, B. (2003). From Genes to Aging in Drosophila. Adv. Genet. 49, 67-109. doi:10.1016/s0065-2660(03)01002-2

Hinnant, T. D., Merkle, J. A., and Ables, E. T. (2020). Coordinating Proliferation, Polarity, and Cell Fate in the Drosophila Female Germline. Front. Cel Dev. Biol. 8, 19. doi:10.3389/fcell.2020.00019

Hniopek, J., Bocklitz, T., Schmitt, M., and Popp, J. (2021). Probing Protein Secondary Structure Influence on Active Centers with Hetero Two-Dimensional Correlation (Resonance) Raman Spectroscopy: A Demonstration on Cytochrome C. Appl. Spectrosc. 75, 1043-1052. doi:10.1177/00037028211028916

Hsu, H.-J., LaFever, L., and Drummond-Barbosa, D. (2008). Diet Controls normal and Tumorous Germline Stem Cells via Insulin-dependent and -independent Mechanisms in Drosophila. Develop. Biol. 313, 700-712. doi:10.1016/ j.ydbio.2007.11.006

Huynh, J.-R., and St Johnston, D. (2004). The Origin of Asymmetry: Early Polarisation of the Drosophila Germline Cyst and Oocyte. Curr. Biol. 14, R438-R449. doi:10.1016/j.cub.2004.05.040

Ishigaki, M., Hashimoto, K., Sato, H., and Ozaki, Y. (2017). Non-destructive Monitoring of Mouse Embryo Development and its Qualitative Evaluation at the Molecular Level Using Raman Spectroscopy. Sci. Rep. 7, 43942. doi:10.1038/srep43942

Ishihara, N., Nomura, M., Jofuku, A., Kato, H., Suzuki, S. O., Masuda, K., et al. (2009). Mitochondrial Fission Factor Drp1 Is Essential for Embryonic Development and Synapse Formation in Mice. Nat. Cel Biol 11, 958-966. doi:10.1038/ncb1907

Jeong, E. B., Jeong, S. S., Cho, E., and Kim, E. Y. (2019). Makorin 1 Is Required for Drosophila Oogenesis by Regulating insulin/Tor Signaling. PLoS One 14, e0215688. doi:10.1371/journal.pone.0215688

Katajisto, P., Döhla, J., Chaffer, C. L., Pentinmikko, N., Marjanovic, N., Iqbal, S., et al. (2015). Asymmetric Apportioning of Aged Mitochondria between Daughter Cells Is Required for Stemness. Science 348, 340-343. doi:10.1126/ science. 1260384

Knoblich, J. A. (2008). Mechanisms of Asymmetric Stem Cell Division. Cell 132, 583-597. doi:10.1016/j.cell.2008.02.007

Kong, K., Rowlands, C. J., Varma, S., Perkins, W., Leach, I. H., Koloydenko, A. A., et al. (2013). Diagnosis of Tumors during Tissue-Conserving Surgery with Integrated Autofluorescence and Raman Scattering Microscopy. Proc. Natl. Acad. Sci. 110, 15189-15194. doi:10.1073/pnas.1311289110

Kosan, C., and Godmann, M. (2016). Genetic and Epigenetic Mechanisms that Maintain Hematopoietic Stem Cell Function. Stem Cell Int. 2016, 1-14. doi:10.1155/2016/5178965

Kumamoto, Y., Harada, Y., Takamatsu, T., and Tanaka, H. (2018). Label-free Molecular Imaging and Analysis by Raman Spectroscopy. Acta Histochem. Cytochem. 51, 101-110. doi:10.1267/ahc.18019
Li, Y., Zhang, W., Fung, A. A., and Shi, L. (2021). Do-SRS Imaging of Metabolic Dynamics in Aging Drosophila. Analyst 146, 7510-7519. doi:10.1039/ dlan01638e

Liang, X., Yan, Z., Ma, W., Qian, Y., Zou, X., Cui, Y., et al. (2020). Peroxiredoxin 4 Protects against Ovarian Ageing by Ameliorating D-Galactose-Induced Oxidative Damage in Mice. Cell Death Dis 11, 1053. doi:10.1038/s41419-020-03253-8

Martin, D. N., and Baehrecke, E. H. (2004). Caspases Function in Autophagic Programmed Cell Death in Drosophila. Development 131, 275-284. doi:10.1242/dev.00933

Matthews, Q., Jirasek, A., Lum, J., Duan, X., and Brolo, A. G. (2010). Variability in Raman Spectra of Single Human Tumor Cells Cultured In Vitro: Correlation with Cell Cycle and Culture Confluency. Appl. Spectrosc. 64, 871-887. doi:10.1366/000370210792080966

May, C. M., Doroszuk, A., and Zwaan, B. J. (2015). The Effect of Developmental Nutrition on Life Span and Fecundity Depends on the Adult Reproductive Environment in D Rosophila Melanogaster. Ecol. Evol. 5, 1156-1168. doi:10.1002/ece3.1389

May-Panloup, P., Boucret, L., Chao de la Barca, J.-M., Desquiret-Dumas, V., FerréL'Hotellier, V., Morinière, C., et al. (2016). Ovarian Ageing: the Role of Mitochondria in Oocytes and Follicles. Hum. Reprod. Update 22, 725-743. doi:10.1093/humupd/dmw028

Mazzalupo, S., and Cooley, L. (2006). Illuminating the Role of Caspases during Drosophila Oogenesis. Cell Death Differ 13, 1950-1959. doi:10.1038/ sj.cdd. 4401892

Moghadam, A. R. E., Moghadam, M. T., Hemadi, M., and Saki, G. (2021). Oocyte Quality and Aging. JBRA Assist. Reprod. 0, 0. doi:10.5935/15180557.20210026

Mok, H. J., Shin, H., Lee, J. W., Lee, G.-K., Suh, C. S., Kim, K. P., et al. (2016). AgeAssociated Lipidome Changes in Metaphase II Mouse Oocytes. PLoS One 11, e0148577. doi:10.1371/journal.pone.0148577

Na, J., and Kim, G. J. (2020). Recent Trends in Stem Cell Therapy for Premature Ovarian Insufficiency and its Therapeutic Potential: a Review. J. Ovarian Res. 13, 74. doi:10.1186/s13048-020-00671-2

Narbonne, P. (2018). The Effect of Age on Stem Cell Function and Utility for Therapy. Cell Med 10, 215517901877375. doi:10.1177/2155179018773756

Park, S.-J., Kim, J.-H., Lee, D. G., Kim, J.-M., and Lee, D.-S. (2018). Peroxiredoxin 2 Deficiency Accelerates Age-Related Ovarian Failure through the Reactive Oxygen Species-Mediated JNK Pathway in Mice. Free Radic. Biol. Med. 123, 96-106. doi:10.1016/j.freeradbiomed.2018.05.059

Parra-Peralbo, E., and Culi, J. (2011). Drosophila Lipophorin Receptors Mediate the Uptake of Neutral Lipids in Oocytes and Imaginal Disc Cells by an Endocytosis-independent Mechanism. Plos Genet. 7, e1001297. doi:10.1371/ journal.pgen.1001297

Partridge, L., Piper, M. D. W., and Mair, W. (2005). Dietary Restriction in Drosophila. Mech. Ageing Develop. 126, 938-950. doi:10.1016/j.mad.2005.03.023

Perrimon, N., Pitsouli, C., and Shilo, B.-Z. (2012). Signaling Mechanisms Controlling Cell Fate and Embryonic Patterning. Cold Spring Harbor Perspect. Biol. 4, a005975. doi:10.1101/cshperspect.a005975

Peterson, J. S., Barkett, M., and McCall, K. (2003). Stage-specific Regulation of Caspase Activity in drosophila Oogenesis. Develop. Biol. 260, 113-123. doi:10.1016/s0012-1606(03)00240-9

Pritchett, T. L., Tanner, E. A., and McCall, K. (2009). Cracking Open Cell Death in the Drosophila Ovary. Apoptosis 14, 969-979. doi:10.1007/s10495-009-0369-z

Puppels, G. J., de Mul, F. F. M., Otto, C., Greve, J., Robert-Nicoud, M., Arndt-Jovin, D. J., et al. (1990). Studying Single Living Cells and Chromosomes by Confocal Raman Microspectroscopy. Nature 347, 301-303. doi:10.1038/347301a0

Ren, Q., Zhang, F., and Xu, H. (2017). Proliferation Cycle Causes Age Dependent Mitochondrial Deficiencies and Contributes to the Aging of Stem Cells. Genes 8, 397. doi:10.3390/genes8120397

Rogina, B., Wolverton, T., Bross, T. G., Chen, K., Müller, H.-G., and Carey, J. R. (2007). Distinct Biological Epochs in the Reproductive Life of Female Drosophila melanogaster. Mech. Ageing Develop. 128, 477-485. doi:10.1016/ j.mad.2007.06.004

Rose, M. R., and Charlesworth, B. (1981). Genetics of Life History in Drosophila melanogaster. II. Exploratory Selection Experiments. Genetics 97, 187-196. doi:10.1093/genetics/97.1.187

Sasaki, H., Hamatani, T., Kamijo, S., Iwai, M., Kobanawa, M., Ogawa, S., et al. (2019). Impact of Oxidative Stress on Age-Associated Decline in Oocyte 
Developmental Competence. Front. Endocrinol. 10, 811. doi:10.3389/ fendo.2019.00811

Schägger, H. (2002). Respiratory Chain Supercomplexes of Mitochondria and Bacteria. Biochim. Biophys. Acta (Bba) - Bioenerg. 1555, 154-159. doi:10.1016/ s0005-2728(02)00271-2

Sênos Demarco, R., and Jones, D. L. (2019). Mitochondrial Fission Regulates Germ Cell Differentiation by Suppressing ROS-Mediated Activation of Epidermal Growth Factor Signaling in the Drosophila Larval Testis. Sci. Rep. 9, 20195. doi:10.1038/s41598-019-55728-0

Sênos Demarco, R., Uyemura, B. S., D’Alterio, C., and Jones, D. L. (2019). Mitochondrial Fusion Regulates Lipid Homeostasis and Stem Cell Maintenance in the Drosophila Testis. Nat. Cel Biol 21, 710-720. doi:10.1038/s41556-019-0332-3

Shi, L., Zhang, J., Lai, Z., Tian, Y., Fang, L., Wu, M., et al. (2016). Long-Term Moderate Oxidative Stress Decreased Ovarian Reproductive Function by Reducing Follicle Quality and Progesterone Production. PLoS One 11, e0162194. doi:10.1371/journal.pone.0162194

Shi, L., Zheng, C., Shen, Y., Chen, Z., Silveira, E. S., Zhang, L., et al. (2018). Optical Imaging of Metabolic Dynamics in Animals. Nat. Commun. 9, 2995. doi:10.1038/s41467-018-05401-3

Shkolnik, K., Tadmor, A., Ben-Dor, S., Nevo, N., Galiani, D., and Dekel, N. (2011). Reactive Oxygen Species Are Indispensable in Ovulation. Proc. Natl. Acad. Sci. 108, 1462-1467. doi:10.1073/pnas.1017213108

Sieber, M. H., and Spradling, A. C. (2015). Steroid Signaling Establishes a Female Metabolic State and Regulates SREBP to Control Oocyte Lipid Accumulation. Curr. Biol. 25, 993-1004. doi:10.1016/j.cub.2015.02.019

Singh, R. D., and Keiderling, T. A. (1981). Vibrational Circular Dichroism of Poly(?-Benzyl-L-Glutamate). Biopolymers 20, 237-240. doi:10.1002/ bip.1981.360200117

Theurkauf, W. E. (1994). Microtubules and Cytoplasm Organization during Drosophila Oogenesis. Develop. Biol. 165, 352-360. doi:10.1006/dbio.1994.1258

Tiwari, S. K., and Mandal, S. (2021). Mitochondrial Control of Stem Cell State and Fate: Lessons from Drosophila. Front. Cel Dev. Biol. 9, 606639. doi:10.3389/ fcell.2021.606639

Toledo, D. A. M., Roque, N. R., Teixeira, L., Milán-Garcés, E. A., Carneiro, A. B., Almeida, M. R., et al. (2016). Lipid Body Organelles within the Parasite Trypanosoma Cruzi: A Role for Intracellular Arachidonic Acid Metabolism. PLoS One 11, e0160433. doi:10.1371/journal.pone.0160433

Uematsu, M., and Shimizu, T. (2021). Raman Microscopy-Based Quantification of the Physical Properties of Intracellular Lipids. Commun. Biol. 4, 1176. doi:10.1038/s42003-021-02679-w
Varkey, J., Chen, P., Jemmerson, R., and Abrams, J. M. (1999). Altered Cytochrome C Display Precedes Apoptotic Cell Death in Drosophila. J. Cel Biol 144, 701-710. doi:10.1083/jcb.144.4.701

Wang, T., and Na, J. (2021). Fibrillarin-GFP Facilitates the Identification of Meiotic Competent Oocytes. Front. Cel Dev. Biol. 9, 648331. doi:10.3389/fcell.2021.648331

Yang, L., Cao, Y., Zhao, J., Fang, Y., Liu, N., and Zhang, Y. (2019). Multidimensional Proteomics Identifies Declines in Protein Homeostasis and Mitochondria as Early Signals for Normal Aging and Age-Associated Disease in Drosophila*[S]. Mol. Cell Proteomics 18, 2078-2088. doi:10.1074/ mcp.RA119.001621

Zanco, B., Mirth, C. K., Sgrò, C. M., and Piper, M. D. (2021). A Dietary Sterol Trade-Off Determines Lifespan Responses to Dietary Restriction in Drosophila melanogaster Females. Elife 10, e62335. doi:10.7554/eLife.62335

Zhang, M., Bener, M. B., Jiang, Z., Wang, T., Esencan, E., Scott III, R., et al. (2019). Mitofusin 1 Is Required for Female Fertility and to Maintain Ovarian Follicular reserve. Cel Death Dis 10, 560. doi:10.1038/s41419-019-1799-3

Zhang, M., Bener, M. B., Jiang, Z., Wang, T., Esencan, E., Scott, R., et al. (2019). Mitofusin 2 Plays a Role in Oocyte and Follicle Development, and Is Required to Maintain Ovarian Follicular reserve during Reproductive Aging. Aging 11, 3919-3938. doi:10.18632/aging.102024

Zimon, A., Erat, A., Von Wald, T., Bissell, B., Koulova, A., Choi, C. H., et al. (2006). Genes Invoked in the Ovarian Transition to Menopause. Nucleic Acids Res. 34, 3279-3287. doi:10.1093/nar/gkl387

Conflict of Interest: The authors declare that the research was conducted in the absence of any commercial or financial relationships that could be construed as a potential conflict of interest.

Publisher's Note: All claims expressed in this article are solely those of the authors and do not necessarily represent those of their affiliated organizations, or those of the publisher, the editors and the reviewers. Any product that may be evaluated in this article, or claim that may be made by its manufacturer, is not guaranteed or endorsed by the publisher.

Copyright (c) 2022 Li, Bagheri, Chang, Zeng, Hao, Fung, Wu and Shi. This is an openaccess article distributed under the terms of the Creative Commons Attribution License (CC BY). The use, distribution or reproduction in other forums is permitted, provided the original author(s) and the copyright owner(s) are credited and that the original publication in this journal is cited, in accordance with accepted academic practice. No use, distribution or reproduction is permitted which does not comply with these terms. 